This item was submitted to Loughborough's Research Repository by the author.

Items in Figshare are protected by copyright, with all rights reserved, unless otherwise indicated.

\title{
A holistic perspective on career development in UK female soccer players: A negative case analysis
}

PLEASE CITE THE PUBLISHED VERSION

http://dx.doi.org/10.1016/j.psychsport.2015.04.003

PUBLISHER

(C) Elsevier

VERSION

AM (Accepted Manuscript)

\section{PUBLISHER STATEMENT}

This work is made available according to the conditions of the Creative Commons Attribution-NonCommercialNoDerivatives 4.0 International (CC BY-NC-ND 4.0) licence. Full details of this licence are available at: https://creativecommons.org/licenses/by-nc-nd/4.0/

\section{LICENCE}

CC BY-NC-ND 4.0

\section{REPOSITORY RECORD}

Gledhill, Adam, and Chris G. Harwood. 2019. "A Holistic Perspective on Career Development in UK Female Soccer Players: A Negative Case Analysis”. figshare. https://hdl.handle.net/2134/20797. 
CAREER DEVELOPMENT IN UK FEMALE SOCCER PLAYERS

1 A holistic perspective on career development in UK female soccer players: A negative case

2

analysis

3

4

5

6

7

8

9

10

11

12

13

14

15

16

17

18

19

20

21

22

23

24

25 
2 Objectives: The purpose of this study was to examine dual career experiences of UK-based

3 female youth soccer players from a holistic perspective with a view to producing a

4 substantive grounded theory of talent development and career transitions in UK female

5 soccer.

6 Methodology: A Grounded Theory methodology (Corbin \& Strauss, 2008) was used.

7 Negative case (Denzin, 1989) former female soccer players $(\mathrm{N}=13)$, their best friend $(\mathrm{N}=13)$,

8 soccer coaches $(\mathrm{N}=4)$, and teachers $(\mathrm{N}=8)$ took part in semi-structured interviews about

9 factors associated with talent development and career transitions in female youth soccer.

10 Results: Multiple social agents (players, team-mates, peers, teachers, parents and siblings) need to optimally interact to ensure that an optimal talent development and learning environment is created. This will provide a supportive holistic talent development environment and lead to adaptive player-level changes that will lead to a greater chance of successful career development.

Conclusions: This study presents a rich understanding of the dual careers of players who did not make it in female soccer. By considering their perspectives alongside of a range of important social agents, we have been able to construct a substantive grounded theory of talent development and career transitions in UK female youth soccer. As a result, these findings may contribute to policy and practice development in UK female youth soccer.

Keywords: Soccer; female soccer; dual career; student athletes; grounded theory; negative case analysis 


\section{Introduction}

2 Within sport psychology literature, the notion of dual careers (i.e., combining sport and education; sport and employment) has gained momentum to the point where it is now considered an international topic that is visible in research from across the globe, including

5 Europe, North America, and Australia (Stambulova \& Ryba, 2014). Given that athletes invest significant time and effort into their sporting and life development careers (O’Neill, Allen, \&

7 Calder, 2013; Stambulova \& Wylleman, 2014) it is perhaps unsurprising that this body of research has gained such momentum, with scholars aiming to support athletes with attaining an optimal balance that will allow them to successfully navigate key life changes, such as; junior-to-senior career transitions, progression through education, and progression to postsport careers (e.g., Stambulova, Engström, Franck, \& Linnér, 2014). As young athletes grow on sporting and interpersonal levels, the number of transitions they face increases and the congruency between their internal and external resources and the demands of a career transition will more likely result in a successful within-career transition (e.g., Alfermann \& Stambulova, 2007; Holt \& Dunn, 2004). As such, recent research-informed political attention has been given to how young athletes might best be supported with their dual careers (e.g., European Commission, 2012).

Despite the importance of athletes’ dual career investments, how athletes view themselves and their endeavours within their dual career experiences is reported to be underinvestigated (Cosh \& Tully, 2014). Moreover, studies that have investigated dual career experiences have tended to investigate multiple sports and both male and female athletes (e.g., O’ Neill et al. 2013; Stambulova et al. 2014). Whilst providing valuable insights into dual career experiences, multi-sport studies may not be sensitive to the nuances of individual sports. One sport that presents quite unique dual career demands on young athletes, is soccer 


\section{CAREER DEVELOPMENT IN UK FEMALE SOCCER PLAYERS}

1 (Christensen \& Sørensen, 2009; Larsen, Alfermann, Henriksen \& Christensen, 2013;

2 McCormack \& Walseth, 2013).

Recently, female soccer ameliorated on a global scale, with 29 million players across

4 the world (Scott \& Andersson, 2013) and greater attention now being paid to the

5 development of elite level female soccer players. For example, Fédération Internationale de

6 Football Association (FIFA) has championed the development of women's soccer on a global

7 scale. As part of this, FIFA (2014) released its women's soccer development programme

8 guidelines (2015 - 2018). This document includes ten key principles for the development of

9 women's soccer; these principles include sustainable and professionalised competitions for

10 female soccer, and having an expert knowledge base involved within decision making.

11 Central to a sustainable professional competition is a sound knowledge base that can promote the effective career transitions - in the context of this study defined as normative or nonnormative turning phases over the course of a female soccer player's career (cf. Alfermann \& Stambulova, 2007) - of female soccer players. In addition, FIFA’s individual nations have developed bespoke soccer development strategies. For example the English Football Association (FA) launched their ‘Game Changer’ strategy for developing women’s soccer (2013-2018) in which they cite the effective transition of youth players to adult players as an important part of the strategy (FA, 2012).

Of particular interest to this special issue; when experiencing player development centres ${ }^{1}$ in the UK, female youth soccer players will often be balancing dual careers in education and sport, as well as attempting to reconcile these within the different stages of adolescence. As a result, these demands may threaten a player's ability to successfully transition the different stages of their career (e.g., from development to mastery/perfection stages; Wylleman \& Lavallee, 2004) or lead to voluntary dropout (e.g., European

\footnotetext{
${ }^{1}$ We use this term to refer to any form of player development centre on the girls' soccer talent pathway in the UK (e.g., Centre of Excellence).
} 


\section{CAREER DEVELOPMENT IN UK FEMALE SOCCER PLAYERS}

1 Commission, 2012). Considered alongside the aforementioned growth and development of

2 female football in the UK, this suggests that greater understanding of talent development and

3 career transitions of female players in the UK may serve to facilitate the balance of players'

4 dual careers and, thus, help to keep talented young players in both their soccer and

5 educational systems. Despite this, little scholarly attention has been paid to these factors in

6 female soccer players (McCormack \& Walseth, 2013). This is an important consideration for

7 the body of research given that it further demonstrates historically reported trends that female

8 athletes in general are typically under-represented in sport psychology literature (e.g.,

9 Conroy, Kaye, \& Schantz, 2008); that female and male athletes will typically have

qualitatively different developmental experiences (e.g., Gill, 2001); and in order to extend

culturally specific understanding, marginalised groups of athletes (such as female soccer players) need to be more visible in dual career research (e.g., Stambulova \& Ryba, 2013; 2014).

With this lack of gender-specific understanding in-mind, Gledhill and Harwood (2014) sought to examine the developmental experiences of elite UK female youth soccer players. Using interviews and fieldwork, they highlighted the meaning attached by elite female soccer players to important psychosocial factors such as support from parents, siblings, soccer friends, non-soccer friends and how they impacted on important developmental factors such as leading a disciplined lifestyle. Moreover, self-regulation and adaptive volitional behaviours were identified as key intra-individual competencies that are central to talent development and career transitions in female soccer players. Finally, using their composite sequence analysis approach, Gledhill and Harwood were able to sequentially structure these developmental experiences which provided a more plausible and developmental understanding of how the different factors associated with talent development changed over time, with the key benefit being that this could then serve to provide applied 


\section{CAREER DEVELOPMENT IN UK FEMALE SOCCER PLAYERS}

1 practitioners with age- and gender-specific advice about important social agents that can

2 positively impact on the development of female soccer players. Despite this, their work was

3 limited by a small and homogenous sample of elite female youth soccer players, which

4 creates the questions of how these research findings inform our understanding of those soccer

5 players who have not favourably transitioned from the development to the mastery stage of

6 their career and highlights a need for a wider range of viewpoints from which researchers can

7 glean a more holistic perspective.

Whilst existing soccer literature allows for inferences to be made about dual careers in soccer, most of these are underpinned by literature examining talent development in soccer and then subsequently extrapolating these findings in to the wider context of career transitions. This has included identifying psychosocial assets of soccer players who are considered elite in their domain (e.g., Gledhill \& Harwood, 2014; Holt \& Dunn, 2004; Van Yperen, 2009) and examining the views of those tasked with developing male soccer players to an elite level (e.g., Morgan, McKenna, \& Nicholls, 2014) in order to suggest qualities that will facilitate normative career transitions in soccer. Frequently, literature has provided confirmatory findings that support the notion of important player-level assets (e.g., resilience, self-regulation) and/or socio-environmental factors (e.g., parental, peer or sibling support) that may positively influence talent development. Collectively, these factors can be conceptually linked with developmental stages offered in non- soccer specific athlete transitions models (e.g., Stambulova, 2003; 2009; Wylleman \& Lavallee, 2004) to allow scholars to understand how players may make successful career transitions. However, given the significant level-bias towards elite youth or adult soccer players, it is difficult to understand the differences between those who do make it and those that don't make it in female soccer. Therefore, to extend current understanding about the complexity of the developmental experiences of female soccer players in the UK from a more holistic 


\section{CAREER DEVELOPMENT IN UK FEMALE SOCCER PLAYERS}

1 perspective, research that examines experiences of lower level players or less-successful

2 players is warranted. One way to address this gap is to adopt a negative case analysis

3 approach (NCA; Denzin, 1989) with female soccer players.

Negative cases have been rarely used in sport psychology literature despite being a

well-established strategy for revising and extending existing levels of understanding (Holt \&

6 Mitchell, 2006). A proposed benefit of the NCA approach is the potential for it to encourage

7 researchers to question pre-existing assumptions about a phenomenon (Patton, 2002) with a

view to broadening understanding and encouraging change where required. For this reason;

we argue that a better understanding of the developmental experiences of female players who

have not advanced to the highest levels of female soccer in the UK (despite having

experienced a female talent development pathway) will extend existing sport psychology

literature as it provides the opportunity to produce a grounded theory of talent development and career transitions in female youth soccer.

Whilst grounded theories of talent development in soccer are present in the existing

literature (e.g., Holt \& Dunn, 2004; Holt \& Mitchell, 2006) these are not culturally or contextually sensitive to the experiences of UK female soccer players. Moreover, existing literature on dual careers (e.g., Stambulova \& Ryba, 2014) has reported that research adopting a holistic perspective (i.e., combining a whole person, whole career and whole environment approaches) is a challenge that will enable scholars to extend current understanding. Combining these arguments with recent calls for contextually and culturally specific understanding in sport psychology literature (e.g., Clarke \& Harwood, 2014; Stambulova \& Ryba, 2014), we contend that a grounded theory approach is warranted. As such, we aim to provide a rich understanding of the experiences of these UK-based negative case players along with other key social agents in order to develop a substantive grounded 
theory that makes proposals about enhancing the chances of talent development and successful career transitions in UK female soccer.

\section{Method}

\section{Ontological and epistemological assumptions}

In a move away from the dominant positivist/post-positivist perspective in dual career research (Stambulova \& Ryba, 2014) we approached this study from an interpretivist philosophical perspective. This perspective focuses on understanding the meanings, purposes and intentions that people attach to actions and interactions therefore could serve to provide clues as to the kind of decisions the players made throughout their developmental experiences. This perspective is consistent with a relativist ontological position in that there are multiple co-existing realities among individuals (Corbin, 2009).

\section{Grounded theory methodology and methodological congruence}

Grounded theory was most useful in this instance where we aimed to generate a substantive theory relevant to this particular area of study with the purpose of offering insight as a basis for future research in an area that has received little empirical or conceptual analysis (Creswell, 2013; Corbin \& Strauss, 2008). We used Corbin and Strauss’ (2008) variant of grounded theory to address the research problem. This variant of grounded theory embraces the constructivist viewpoint in that "concepts and theories are constructed by researchers out of stories that are constructed by research participants who are trying to explain and make sense out of their experiences and/or lives, both to the researcher and themselves" (p.10). Corbin proffers that generating concepts in this way serves to increase understanding of peoples' everyday lives, whilst also leading to discussion and debate which can further develop understanding. This mode of concept generation is consistent with our rationale for the adoption of a NCA-based study. Therefore, the selected variant of grounded 


\section{CAREER DEVELOPMENT IN UK FEMALE SOCCER PLAYERS}

1 theory was consistent with the philosophical underpinning and aims of our study, thus

2 demonstrating methodological congruence (Mayan, 2009).

\section{Theoretical sensitivity}

Whilst one can arguably not enter a study with a completely clean slate; Corbin and Strauss (2008) do contend that new grounded theory studies should not begin with a predetermined framework or set of concepts. There are certain exceptions to this; including when existing frameworks can be used to demonstrate how a phenomenon is only partially understood, thus providing a conceptual context from which research progress (Maxwell, 1996). In the context of our study and consistent with Corbin and Strauss' (2008) viewpoint, we used existing literature (e.g., Gledhill \& Harwood, 2014; Holt \& Dunn, 2004) to: (a) affirm only partial understanding of talent development and career transitions in female soccer; and, (b) develop initial questions and ideas for theoretical sampling.

\section{Sampling and participants}

Purposive sampling (Patton, 2002) was initially adopted as grounded theory research begins by recruiting participants who are presumed to be able to provide data that will best address the research problem. Accordingly, after gaining ethical approval from a UK-based University, participants were invited to take part in a study about women's soccer and were told that the over-arching aim was to provide recommendations for enhancing the chances that female soccer players would have a successful career within soccer. We sampled 13 female participants $(\mathrm{M}$ age $=19.61 \pm 1.19)$ who were initially retrospectively interviewed about their experiences as a developing female soccer player. They had accessed player development centre coaching for between 3-7 years $(\mathrm{M}=4.62$ years \pm 1.85$)$ prior to withdrawing from competitive soccer. The mean time since withdrawal from soccer ranged from 1-4 years $(M=2.28 \pm 0.9)$. Inclusion criteria were that participants were (former) female soccer players aged 18 or over (this is normally the age that access to player development 


\section{CAREER DEVELOPMENT IN UK FEMALE SOCCER PLAYERS}

1 centre coaching at a local or regional level ceases) who have experienced a player

2 development centre programme but not progressed into either Women’s Premier League,

3 Women's Super League, or international teams at either age-group or senior international

4 level. All participants in the study had successfully transitioned through compulsory

5 education and post-compulsory (16-19 years old) education in the UK. Nine of the 13 players

6 in the study were working towards a higher education qualification at the time of the first

7 interview and two had successfully completed a higher education qualification at the time of

8 the first interview.

9

Data was collected through in - depth, semi - structured interviews with players ( $\mathrm{n}=13$, ranging from 42 minutes -91 minutes). The interview guide was based on previous soccer-specific talent development literature (Gledhill \& Harwood, 2014; Holt \& Dunn, 2004); and was provided to players prior to the interview so that they could consider the focus and nature of the interview to increase the richness of data (cf. Christensen, 2009). Players were questioned about their experiences of growing up as a female soccer player (e.g., Can you talk to me about what it was like growing up as a girl that was good at soccer?; What challenges did you face as a female soccer player?); Peer-relationships (e.g., Did / How did your friends in / out of soccer help you to develop as a soccer player?); Parents (e.g., Can you talk to me about your parents' involvement in your soccer career?); Coach relationships (e.g., Can you talk to me about your relationship with your coach/coaches?; What types of activities did you do at practice?; Did coaches pay equal attention to different aspects of your development, such as technical and psychological?); and the interview guide was refined and developed as interviews progressed. Interview questions consisted of main questions, probe questions, and follow - up questions to ensure accurate understanding of responses (Rubin \& Rubin, 2005). Data was recorded and transcribed verbatim. 


\section{CAREER DEVELOPMENT IN UK FEMALE SOCCER PLAYERS}

Data collection and analysis was an iterative cycle. Analysis began as soon as the first data were collected (Corbin \& Strauss, 2008), with initial analysis leading to further data collection, theoretical sampling and data analysis (Holt \& Tamminen, 2010). Throughout the initial 13 interviews with players and the subsequent data analysis, a number of concepts emerged that led to the theoretical sampling of additional social agents who were deemed to have influenced the players' developmental trajectory (see Fig.1). As emerged relating to the player-coach dyad and role strain, we sequentially sampled the following: Former coaches of the players $(\mathrm{N}=4$; male $=3$, female $=1)$, the best friend $(\mathrm{N}=13$; female $=13)$ and former teachers $(\mathrm{N}=8$; male $=6$, female $=2)$.

Coaches were qualified to UEFA 'B' $(n=3)$ and UEFA 'A' $(n=1)$ license level, coaching experience ranged from 6 - 24 years, and all coaches had experience of coaching male and female players (including coaching female players who have progressed to either youth or senior female international soccer). They were theoretically sampled to glean information about the concepts of coach-player relationships, coach-team mate relationships, coach perceptions of female soccer, and coach perceptions and experiences of working with players of different ability levels. Coaches were interviewed first about their views on female soccer and how it had developed in recent years. Interviews with coaches ranged from 30 113 minutes. This initial unstructured element was to develop an interview rapport with the coaches to facilitate the richness of data (Rubin \& Rubin, 2005). As the interview progressed, we then discussed the coaches' behaviours in a more general manner (e.g. "Can you tell me how you try to engage a broad range of abilities in single coaching sessions?”), followed by progressing the interview on to more specific aspects that the players had raised (e.g. "Have you ever witnessed times when players have been given preferential treatment by coaches because of their advanced playing ability?”). 


\section{CAREER DEVELOPMENT IN UK FEMALE SOCCER PLAYERS}

Interviews with the player's 'best friend' centred on the social experiences of being an

2 adolescent female to examine the concepts of peer relationships, the nature of peer

relationships, factors affecting these peer relationships and the impact of peer relationships on talent development and career transitions. Interviews ranged from $42-45$ minutes. These interviews began with the first author posing questions regarding the lived experiences of the peers (e.g. “Can you tell me about your friendship with...during your time at school/College?”). Questions increased in specificity to the social life (e.g. “Can you talk me through your social lives during your time at school /College?”). Finally questions progressed on to relationship specific questions (e.g. "Did you ever play a role in helping your friend develop as a football player?” or “Can you talk me through your most memorable moment with your friend?”). No data was recorded regarding the length of friendship; however events recounted indicated that friendships had been in place for at least six years at the time of first interview.

Teachers were qualified to Masters level $(n=6)$ or undergraduate level $(n=2)$, all of which were in either leisure studies, sport and exercise sciences or physical education related areas. Their teaching experience ranged from 5-23 years. All teachers were in possession of a relevant post-graduate level teaching qualification and they had worked with players in teaching and/or pastoral support capacities for two years. They were theoretically sampled to examine the concepts of: teaching talented female soccer players; teacher - player relationships; teacher - parent relationships; teacher views of female soccer; and the career prospects of female soccer players. Teacher interviews also had an initial unstructured element that centred on the teachers' experience of working with talented athletes (e.g. "Can you tell me about a time when you have taught or tutored a talented young athlete?”). After this, interviews progressed on to more specific aspects of the teaching experience (e.g. "Can you talk me through any of the challenges of teaching talented young soccer players?”). 


\section{CAREER DEVELOPMENT IN UK FEMALE SOCCER PLAYERS}

1 Finally, the interviews progressed on to more specific issues presented during the player

2 interviews (e.g. "How do you try to support talented young soccer players to reconcile their

3 roles as student-athletes?”). Interviews with teachers lasted 37 - 52 minutes.

These additional social agents were sampled to gain a richer understanding of how the

5 different interactions between multiple social agents could impact on talent development and

6 career transitions in female soccer, with the intention of achieving theoretical saturation

7 (Corbin \& Strauss, 2008). Data collection was discontinued when it ceased producing new

8 insights (cf. Morse, 1995).

9 Data analysis and methodological rigor

We engaged in iterative data analysis with a view to achieving an adequate level of theoretical saturation (Corbin \& Strauss, 2008). Three stages of coding were used during data analysis. First, open coding was conducted with the audio and written data to identify the initial concepts and their meaning for talent development and career transitions in female soccer. For example; initial concepts of 'peers' perceptions of female soccer', 'peers' role in lifestyle choices', and 'soccer peer expectations' were constructed from the data and subsequently grouped under the initial category of 'player - peer interactions'. Through axial coding, relationships between concepts and categories were explored so that we could form more precise categories. For example; 'player-peer interactions’ was explored further and broken down into more precise categories of 'player and team-mate interactions' (which was refined further still to 'coach, player and team-mate interactions') and 'player and non-soccer peer interactions' (which was later refined further still to 'player, non-soccer peer and sibling interactions'). During theoretical integration (Corbin \& Strauss, 2008), we re-constructed the data into the explanatory model (Fig. 2) in which we encapsulated the relationships between the core and underpinning categories. 


\section{CAREER DEVELOPMENT IN UK FEMALE SOCCER PLAYERS}

Memo-writing and diagramming were used to explain and develop relationships between concepts and to aid reflexivity on the part of the researchers (Corbin \& Strauss, 2008). Diagramming primarily was used to develop the appearance of the theoretical framework and to organise thoughts about the relational nature of concepts.

Member reflections (Tracy, 2010) took place to allow a process of elaboration and collaboration with the research participants to "throw fresh light” (Bloor, 2001, p. 395) on our interpretations. The first author individually presented participants with results and asked them to openly critically comment on the findings (e.g., did the quotes display what mattered and the [multiple] meaning[s] behind what mattered? What thoughts did they have about the theoretical framework and proposals?). Two other experts in sport psychology literature, including the second author (both of whom have extensive experience of grounded theory research), one female soccer coach with extensive experience of playing and coaching women's soccer in the UK (otherwise unrelated to the study), and one male Head of Sport Science and Medicine with extensive experience of working with talented female youth soccer players (otherwise unrelated to the study) were also asked to comment on the general presentation of the diagram and the theoretical proposals. Collectively, comments contributed to the final layout of the theoretical framework. These processes were designed to add to the credibility of the research by examining the degree to which participants and other potential 'end-users' of the research found it both comprehensible and meaningful (Tracy, 2010).

After producing the final theory and confirming the central proposals, we conducted an extensive review of literature. Initially we focussed this review on studies that demonstrated positive cases of talent development in soccer (e.g., Gledhill \& Harwood, 2014; Holt \& Dunn, 2004) or factors considered important for talent development in soccer (e.g., Mills et al. 2012; Morley et al. 2014). This was followed by a broader consideration of wider literature associated with developmental considerations presented through the grounded 


\section{CAREER DEVELOPMENT IN UK FEMALE SOCCER PLAYERS}

1 theory, such as; learning (e.g., Eisenkopf, 2010), self-regulation (e.g., Toering et al. 2009),

2 role strain (e.g., Goldberg \& Chandler, 1991), career transitions (e.g., Stambulova et al. 2012)

3 and dual career experiences (e.g., Stambulova et al. 2014). In doing so, this allowed us to

4 permeate into our analysis the second viewpoint of the cultural praxis of athletes' careers

5 paradigm (Stambulova \& Ryba, 2014). This highlights the need for inter- or trans-

6 disciplinary understanding when interpreting athletes' lived experiences, as they are too

7 multidimensional and interactional to be fully grasped through one perspective alone. The

8 focus of the extended, post-theoretical literature review was to consider the oppositely

9 congruent nature of our themes with existing positive case-based literature; in order to refine

10 and interpret our findings (Strauss \& Corbin, 1998) in a positive frame, to lend conceptual

support to the proposals that an absence of these negative conditions may lead to a greater chance of talent development and successful career transitions in female youth soccer.

Results

The processes outlined in the method led to the development of a substantive grounded theory of talent development and career transitions in female youth soccer that was constructed around the core category of optimal social interactions enhancing the chances of successful talent development and career transitions. In the context of this study, we define social interactions as communications or collaborations involving two or more people that can influence the way in which those people work with each other within a talent development and career transitions social milieu. This core category is underpinned by two categories: (1) Developing a supportive soccer talent development context; and (2) Developing the player. With reference to these categories, the first part of the results demonstrates the experiences of players and other social agents influential in talent development and career transitions in female youth soccer. In keeping with the interpretivist nature of the study, we have used multiple sub-headings and rich quotes from multiple 


\section{CAREER DEVELOPMENT IN UK FEMALE SOCCER PLAYERS}

1 participants to piece together the implicit meaning (Cresswell, 2013) of these experiences for

2 the career transitions of female soccer players in the UK. We adopted this tactic being

3 mindful of the following: the need for clearly articulating the multidimensionality of career

4 transitions (Stambulova \& Alfermann, 2009) on intra-individual and socio-cultural levels;

5 and in an attempt to answer calls for a greater interactional understanding (i.e., between the

6 player and their environment) of developmental experiences in soccer (e.g., Mills et al. 2012).

7 Finally, the grounded theory and key theoretical proposals are presented at the end of the

8 results.

$9 \quad$ Player, teacher and parent interactions, and role strain

Between the ages of 13-15 years, it was clear that normative behaviours in the players' social circle pointed towards more of an 'adult' lifestyle which players were drawn in to. By 15 years old, many of the players in our study had started to place greater value on their 'normal teenage' identity as opposed to their 'soccer' identity. This was primarily due to the normative social behaviours of non-soccer peers and, where applicable, the player's older sibling (s). As players moved between 15-17 years old, players and their best friends began to place greater emphasis on going out drinking with friends. Players reported doing this on the night before training or games and sporadically missing training or games because of their resultant 'hangover'. This would often be disguised to parents by telling parents that they “felt ill” [Jordana] as players reported that often their parents “Didn’t have a clue what I was doing because I just said I was staying at a friend’s [house]” (Leigh-Anne; Bryony).

From 14-16, players also experienced significant role overload from their teachers as the important General Certificate of Secondary Education (GCSE) examinations took priority in education. Given the importance of the GCSEs for one’s educational future, teachers engendered or enforced the 'student' role identity of the players, often drawing on parents to 


\section{CAREER DEVELOPMENT IN UK FEMALE SOCCER PLAYERS}

1 reinforce this. As such, it was during this age that players further developed their non-soccer

2 role identity, despite them still being actively involved in soccer.

From 16-18 years, players were socialized further still into non-soccer role identities,

4 despite many of them wanting to - at 16 - still focus attention on playing football.

5 Specifically, players cited teachers discussing that “girls can’t be professional soccer players

6 yet as there isn't a structure for it” (Jemima), parents invariably supporting the standpoint of

7 teachers and prioritizing education over soccer, and, in some cases, coaches emphasizing the

8 importance of education (e.g. "If I ever said I was struggling with school work, my coach

9 always told me that was the priority” [Bryony]). During this time period, parents would often

support the teacher's requirements for educational success, even to the extent of banning players from attending training or games unless they had caught up with work.

Teachers highlighted different approaches to student support between elite and nonelite players from the point of view of facilitating their soccer involvement. The teachers' professional outlook appeared to be underscored by the playing level of the student-athlete and the teacher's perception of whether the player had a chance of 'making it':

“I work differently with the girls who are representing [youth international team] to career out of it...plus there's no point me trying to stop them going off to camps because they'll just go anyway and I know that their mum or dad will support them in that decision. It is easier for me to get the parents on side if their daughter doesn't play for one of the top teams or play at youth international level because then I can justify their education and can reconcile the greater value of it against their football. Yes, I would love for them all to make it because that is their passion, but I know that most of them won't so I have to meet that demand for them as well, as much as they don’t like it sometimes.” (Michaela). 


\section{CAREER DEVELOPMENT IN UK FEMALE SOCCER PLAYERS}

1 Jack (a teacher) demonstrated a different perspective that highlights the role demand of

2 teachers and the impact of institutional demands on teachers' decision making:

"It's great that we have some talented student-athletes. Good for the marketing for [College]. But they have to realise that they are students first and athletes second. I have to get them through their qualifications and if I don't, I get my boss on my back. Most - if any - of these [players] won’t have anything like a professional career so I need to make sure that the end result for them, and me, isn’t a fail statistic. If soccer has to go for me to ensure that, then so be it.”

\section{Player, non-soccer peer and sibling interactions, social competence, and role strain}

The following passages provide evidence of the female players’ inability to manage the role conflict that emerged between their role as a female soccer player and their role as an adolescent female. Players had witnessed the lifestyle of youth international players (usually their team-mates or close friends within soccer) and did not want to have to give the commitment required to maintain that lifestyle:

Leigh-Anne: "I mean like, I saw what the [international] girls had to do to play there; keeping food diaries, training every day, away from their family playing all the time, 'don’t do this, don't do that'; no way was that for me!”

Maladaptive lifestyle choices (e.g., prioritising social life, nights out drinking over soccer as they entered early - mid teenage years) were key indicators of a lack of discipline, lack of sacrifice and, thus, a lack of social competence:

Leigh-Anne: “I could have been like 'no, I want to concentrate on this [my soccer]' but I didn't, I'm quite easily led in a way and I just wanted to be like everybody else...”

All players reported having non-soccer friends who were focussed on leading a 'normal teenage lifestyle' involving lots of nights out drinking. This impacted on the role 


\section{CAREER DEVELOPMENT IN UK FEMALE SOCCER PLAYERS}

1 strain experienced by players as there was a degree of role conflict between the 'female

2 soccer player' role, and the 'adolescent female' role. Developing players tended to be

encouraged by peers to 'follow the crowd'. Some players felt they lacked a peer social

support network that would help them to lead a disciplined lifestyle. For example, when asked if she felt she had that type of support, Bryony responded with "no, not really...sometimes my team-mates were even worse than my friends outside soccer for that!” and Melanie (her best friend) recounted numerous examples of their social lives as crystallising experiences in their friendship:

Melanie: "I think my best memory is a house party at mine when we were about 13. My parents weren't there so we had loads of friends round and raided the spirits cabinet. We did not feel well after that! Then I remember the first time we went into town together. We were about 16 and because we were bigger than a lot of people our age, we could get in everywhere, but Bryony’s big sister came with us just in case [laughs]. We thought that if we had some older people with us it would make it easier to get in places.”

Other players appeared concerned about their peers’ perceptions of their sexual orientation, a perception that players felt was created by them playing soccer. The passage below from Leigh-Anne demonstrates how these factors combined to influence her lifestyle choices:

Interviewer: Did you ever find it difficult being a teenage girl that was good at soccer?

Leigh-Anne: “Ha ha! Fucking hell yeah! Nobody played soccer near me! Everyone thought that girls that played soccer were just lezzers [a colloquial term to indicate peers believe female soccer players are homosexual] which when I look back now doesn't matter; but at 13, 14, 15 it's hard if all your mates are saying that....and all my 
mates just wanted to get pissed. I think I had my first drink when I was about 13 because that's what all my mates did. When I got to like 15 or 16, everyone just wanted to get out into town so that we could seem like we were more grown up. By the time I was 18 I was just playing soccer for fun really and I didn’t really need to work that hard to be good”

\section{Player, coach and team-mate interactions; psychological wellbeing and behavioural}

\section{disaffection}

Coaches and players in our study reported coach level behaviours that players perceived as inequality of opportunity, thus threatening a player's psychological wellbeing. Players referred to this perceived inequality of opportunity as coaches having 'favourites' within the team. These favourites were perceived to be the youth international or regular firstteam players:

Jordana: “when you're looking at players like [first-team player] and they’re pretty much allowed to do what they want, you kind of think 'well, why should I bother?' The coach definitely had his favourites and a lot of us just felt left out most of the time because we weren't as good as them. I hardly ever had any one-one feedback from my coach because he was always more bothered about getting the best players sorted out, but if I ever did anything wrong he'd bollock me...but if they missed training cos they basically couldn't be arsed for whatever reason, he never said anything to them.”

Interviewer: How did you feel about that?

Jordana: “It was weird for me. Like I played soccer since I was like 10 and I’ve always been pretty good to be fair...well alright, better than a lot of people (laughs)...but like when I played at the centre, I started and went straight into the first team after the first training session, and thought 'this is great' but then I'll always 
remember the coach's first team-talk...he said to us that we had to make sure that we got the ball to either [youth international player] or [international rep squad player] as much as we could because we were playing [the best team in the league]. I just thought that we may as well all just fuck off home and leave them to it! ... I just felt like I was rubbish, like the coach didn't trust us with the ball when he kept saying just pass it to [youth international player]...I didn’t tell him that though.”

Some of the players in the study that had been highlighted as 'better' players by their coaches reported a lack of concern about their lifestyle choices at the time because they knew they were technically more competent than their counterparts.

Melissa: “I knew I was better than a lot of the other players so wasn’t too worried and I knew that the coaches wouldn't say anything to me” Interviewer: Can you give me an example of what you mean by that? Melissa: "Well, like when I went on the lash [a colloquial term to indicate a night out drinking alcohol with friends] one student night and got absolutely smashed [a colloquial term to indicate becoming inebriated]. I texted my coach the next morning and said that I couldn’t make training cos I was ill. He asked if I was ill or if I'd been out. I just said a bit of both really and his first response was asking me if I'd still be ok to play the day after because it was a big game and he needed me there.” Interviewer: So how did this approach from your coach make you feel then? Melissa: "To be fair, I knew I could pretty much get away with what I wanted. As long as I turned up and performed, I don't think he was too bothered. Yeah, it was like that for a few of us because we were better players so the coaches gave us a bit more leeway than some of the players that weren't as good”

In order probe this notion further, we asked Geoff (coach) if he had ever witnessed or even adopted such approaches: 
“[After pausing for thought and making eye-contact] Yes. The prestige of having a girl get to youth international from your centre is important. It is a way of attracting more players, adding credibility to the work you do etc. Sometimes that means the better players get more attention than the other players, sometimes that means they get preferential treatment when they might want to miss a session here or there if they don’t think they need to attend.”

The coach and player-level findings from this study suggest that coaches were viewed as, and felt, technically and tactically competent or confident; yet were less-so with the psychosocial development of their players. For example, Eleanor highlighted how her coach would tell her frequently “you need to be more confident”, but did not offer any advice about how she may develop this confidence, nor did he ever explain to her why he felt she lacked confidence beyond saying she was quiet. Similarly, Bryony commented how her coach told her “you need to be less scared when you're a goalkeeper” but was unable to support her development, telling her "it is something that will come to you eventually”. Michael articulated some of the problems facing coaches in girls' soccer:

“I think a key problem is that we don’t have the expertise, is that the right word? Yes expertise or probably the knowledge...to be able to provide everything the girls need. Don't get me wrong, I'm a coach and I'm a bloody good coach. Put me on the grass and I'm happy, but am I a sport psychologist or a lifestyle consultant or whatever else? No. Do we have the potential to offer everything a player needs? With my contacts, yes. With the money we get? ...I would love to, but it goes back to what I said earlier, the money needs to go to coaching the players.”

Players reported a perception that the higher level players had unrealistic expectations and/or could not communicate their expectations in an appropriate manner. In addition; at different points in their career, players perceived themselves to be less competent than either 
team-mates and/or opponents whilst still wanting to be the best. The following passage from Anne-Marie encapsulates these issues:

“I'm the same in everything... I want to be the best and if I'm not the best then I just give up because I don't enjoy it. I don't really understand... and if I'm not [the best] then I don’t see any point trying...So when you've got [youth international soccer player] barking at you for misplacing a pass in training, or ... because you scored an own goal, you are going to doubt yourself; aren't you? ”

\section{Perceptions of football career opportunities and player-teacher interactions}

There was a perceived lack of career opportunities in the UK. Lizzie articulated the lack of soccer career opportunities, particularly for young female soccer players, and how this impacted on her career transitions:

“[After starting College] When I wasn’t in College or in lessons, I’d work...it wasn’t that I didn’t want to go; give me a choice of football or work and I’d pick football any day, but I didn't get paid [like male players of the same age and standard] and I needed the money...I understood when the coaches didn’t pick me because I couldn’t go to training.”

As a result, players felt a sense of role ambiguity when questioned by significant social agents (e.g., teachers) why they might prioritise soccer. As players were unable to cite any tangible reasons other than enjoyment or social interaction, teachers would often go through an informal process of cognitive reframing that encouraged student-players to ascribe greater value to their 'student' role rather than their 'soccer player' role. Often this was achieved through emphasizing the importance of education for long-term career planning, economic stability and quality of life. As a result of these interactions, the role identity and value with the 'soccer player' was diminished as the role identity and value of 'student' increased. For 


\section{CAREER DEVELOPMENT IN UK FEMALE SOCCER PLAYERS}

example, Jordana discussed an experience she had with her progress tutor at College which resulted in a wholesale alteration in her role values:

"I was in a disciplinary meeting with my progress tutor part way through my first year in College. He said to me that I was in danger of being kicked out because I was too far behind on my coursework and my grades weren't up to scratch. That for me was like ‘time to make a decision’. He talked me through [asked] why I was missing so many deadlines and it was mainly because [of soccer training and matches]. When I explained this to him, he basically said that if I wanted to make anything of myself then football had to go. I spoke to my parents about it and they agreed that education was my priority so I quit football pretty much altogether.”

Coaches were also asked their opinions about the potential opportunities for a sustainable career in female soccer. Michael provided a useful insight into his perception of career opportunities.

“The problem for our girls is where do they go when they leave us? For a lot of them there is nowhere to have a career. The good ones might get picked up by a FAWSL [Football Association Women’s Super League] club if they're lucky, others will go get a scholarship in America. We're lucky we’ve had a few get to [youth international] so they'll probably have a playing career if they want, especially now how the FAWSL is going [progress of professionalization of the FAWSL]. Outside the FAWSL they can't make a living playing football. Trying to make a professional career as a coach is not much easier because of the culture in men's football...”

\section{Theoretical proposals}

Three key proposals are represented in the grounded theory of talent development and career transitions in female soccer (Fig.2). Prior to these proposals and in keeping with recommendations for grounded theory research (e.g., Weed, 2009; Tamminen \& Holt, 2010), 


\section{CAREER DEVELOPMENT IN UK FEMALE SOCCER PLAYERS}

1 we shall first outline the point of departure from previous literature. Previous soccer literature

2 (e.g., Gledhill \& Harwood, 2014; Holt \& Dunn, 2004) indicates that soccer players usually enter a talent development programme because they have demonstrated signs of age-specific above average ability. Given the empirical support for this notion, we have accepted this as

5 the starting point for a female soccer player's career transitions, and also cite this as our point of departure. The first proposal (Box 2; Fig. 2) is that players, coaches, teachers and parents need to adaptively interact to produce an optimal talent development learning environment (TDLE). As a parallel process, optimal bi-directional interactions need to take place between players and siblings, and between players and peers both in soccer and out of soccer. Players, coaches, teachers and parents require optimal interactions in order to lay the foundation for manageable, effective participation in a talent development programme for female soccer players. This is in order to facilitate access to a talent development programme and, thus, provide access to valuable resources for learning and psychosocial development as a soccer player. Soccer peers are noteworthy in the talent development environment for creating an effective motivational climate which challenges players at an appropriate level, with players of differing levels being important 'learning assets' for their team-mates. Non-football peers and siblings have an apparently significant role to play in helping talented female soccer players develop an enhanced level of social competence through appropriate levels of social motivation which determines their degree of sacrifice and discipline. Ubiquitous from all participants in our study was that, if one (or more) interaction (s) within the social environment becomes sub-optimal (e.g., breakdown in player and teacher relationship because of educational under-performance), the player level outcome will be a reduction in the likelihood that they will progress to an elite level in soccer, but may enhance their career development in other areas (e.g., progressing their education career). 


\section{CAREER DEVELOPMENT IN UK FEMALE SOCCER PLAYERS}

The second key proposal (Boxes 3 and 4; Fig 2) is that the optimal multi-agential interactions cited above will result in a perceived need supportive talent development environment (STDE). We define a STDE as an environment where players perceive they have sufficient access to football specific advice and guidance; they will have opportunities to develop; will be faced with realistic expectations and functionally relevant challenges from their coaches, soccer-peers and teachers; they will have access to appropriate lifestyle management resources; and they will be able to develop strategies to manage role strain. The cumulative outcome of this supportive environment will be effective player-level role strain management. Through being in a STDE, players will have more chance to develop key intraindividual psychosocial assets (e.g., self-regulation), will experience enhanced psychological wellbeing, and will display more adaptive psycho-behavioural characteristics (e.g., training and rehabilitation adherence, volitional reflective behaviours, and lifestyle management).

The final proposal (Box 5; Fig 2) is that for talent development and successful career transitions to continue throughout a player's senior career, the factors cited above must continue to function in a cyclic nature where internal and external resources adapt to reflect the demands of the playing level.

\section{Discussion}

The aim of this paper was to produce a substantive grounded theory of talent development and career transitions in female soccer. A unique feature of this study was that we examined the dual career experiences of those who did not make it to the highest level of female soccer in the UK despite having experienced a female specific talent development pathway, thus enhancing understanding of a participant group who have previously been marginalised in career research (cf. Stambulova \& Ryba, 2014). A further unique feature was the theoretical sampling of social agents currently under-represented in existing literature (e.g., teachers, non-sport peers) to assess the interactional role of these transitional variables 


\section{CAREER DEVELOPMENT IN UK FEMALE SOCCER PLAYERS}

1 (Stambulova 2003; 2009) on career development in UK-based female soccer players. In

2 doing so, we have adopted a holistic perspective (Wylleman \& Lavallee, 2004) on the

3 developmental experiences of negative case female soccer players. Moreover, based on our

4 findings, we have made proposals regarding the transitional outcomes (Stambulova, 2003;

5 2009) of female soccer players in the UK. The final unique feature of this study was that we

6 moved away from the reported trend of post-positivist approaches in career transitions

7 research (see Stambulova \& Ryba, 2014) to a more interpretivist approach that has allowed

8 us to produce a contextually sensitive substantive grounded theory of career transitions and

9 talent development in UK female soccer.

Our player-level findings mirror those reported in contemporary career transitions

literature (e.g., Pummell, Harwood, \& Lavallee, 2008; Stambulova et al. 2014; Stambulova et

al. 2012; Stambulova \& Wylleman, 2014) in as much as players struggled to balance the

demands of soccer, their academic studies and their private life. By also concurrently

considering the perspectives of multiple social agents within a player's developmental

trajectory alongside those of the player; we aim throughout this discussion to present a deeper understanding of how and why players may struggle to reconcile these roles. Throughout the discussion we elucidate considerations congruent with achieving positive developmental outcomes and close by offering applied implications which we feel will aid long-term talent development and dual-career transitions in female youth soccer. By discussing findings in this manner, we respond to research calls (e.g., Stambulova \& Ryba, 2014) by demonstrating a greater understanding of what UK female youth soccer players' careers are, how they depend on the contexts the players belong to, and how we can help players to optimise their holistic career development.

Adolescent females have historically been demonstrated to have multidimensional self-identities (e.g., Goldberg \& Chandler, 1991). These identities vary based on sport and 


\section{CAREER DEVELOPMENT IN UK FEMALE SOCCER PLAYERS}

non-participation which presents the potential for role strain, which can lead to players struggling to manage multiple roles (e.g., O’Neill et al. 2013). Role strain is made up of role under load, role overload, role conflict and role ambiguity. The multi-agential relationships within a player's socio-contextual environment have the potential to create significant role strain as well as impacting on a soccer players' role identity and values. We suggest that these player-level difficulties may in part be due external pressures placed on other social agents. For example; a teacher's concern about a student failing - or not being a high achiever on an academic course - because soccer takes up time away from their studies was created by organisational demands placed on the teacher. This had a residual impact on the player because of the way teachers then interacted with players and their parents (e.g., suggesting that players give up soccer in favour of academic studies; encouraging parents to enforce withdrawal from soccer). This suggests that the interactions between players, teachers and parents became transition barriers (Stambulova, 2003; 2009) for players' soccer careers, but better aided their normative transitions in their education careers. Resultant from this, the expectations and behaviours of teachers and parents had shaped the players' values (Schwartz, 2006) away from soccer towards more socially appreciated roles (cf. Roccas \& Sagiv, 2010); such as being an effective student who engages in optimal life planning (e.g. planning for higher education, planning their non-soccer career). When combined with the perception from players, coaches and teachers about the lack of opportunities for playing careers or professional careers (e.g., in coaching roles) upon finishing their playing careers (cf. McCormack \&Walseth, 2013); these interactions with significant social agents resulted in soccer players becoming role under-loaded in their 'soccer player' role. These findings are consistent with recent dual career research (Stambulova et al. 2014) which highlighted that athletes who did not see their sport as a viable, economically stable career placed greater value on their educational studies. 


\section{CAREER DEVELOPMENT IN UK FEMALE SOCCER PLAYERS}

As players became role under-loaded in their role of soccer player, this contributed to a role overload in their role as a 'normal' adolescent female. By being given permission to miss training and games, or facing no sanctions for missing these voluntarily, high-level players placed less value on leading a disciplined soccer lifestyle. This finding is stark given the widely held notion of lifestyle discipline being a determinant of talent development in soccer (e.g., Morley et al. 2014). As a result, players would focus more on enjoying a 'normal' mid-late adolescent teenage life of socialising with friends. This change in role emphasis, particularly in mid-late adolescence, created an increased sense of role ambiguity where players did not know which role they would value the most or which they should be adopting. When non-soccer peers and siblings began to have more of an influence on the soccer players in our study, this would often result in role conflict as the soccer players were no longer clear about which role they would prefer to fulfil: Soccer player or 'normal' adolescent female (cf. Wylleman \& Lavallee, 2004). When this occurred, they attempted to fulfil both roles, which typically resulted in sub-standard performances during training or games; and subsequently being dropped from the team. When this happened, players decided to de-select themselves from training and then from matches, initially asking more to play in reserve teams to avoid the competitive demand before withdrawing from soccer altogether. Whilst existing literature (e.g., Wylleman \& Lavallee, 2004) discusses how multiple transitions through adolescence, education and sporting careers can create difficult life situations for athletes, examination of existing soccer literature indicates that role-strain is not yet widely understood. Our findings are oppositely congruent with dual career research with elite athletes which reported that they were required to focus their areas in two areas of achievement whilst concomitantly balancing their academic, sporting and social roles (Bruner, Monroe-Chandler, \& Spink, 2008). Therefore, to support the propositions within our 


\section{CAREER DEVELOPMENT IN UK FEMALE SOCCER PLAYERS}

1 grounded theory we contend that greater scholarly consideration of role strain in UK female

2 soccer would make a noteworthy contribution to the literature.

In a performance environment, effective interaction between players, coaches and

4

team-mates is central to the learning that can take place which, in turn, is central to the development aspect of talent development. Players appeared to demonstrate a decreased enactive mastery, typically born out of negative social comparisons, which then impacted on self-efficacy and intrinsic motivation. These negative social comparisons were initiated by; the player, their higher level team-mates, or the coach.

Coaches in this study demonstrated an "it is what they do with a ball that is important” attitude. We interpreted this coach philosophy as a contributing factor in the lifestyle choices displayed by players and impacting on basic psychological need satisfaction (e.g., Deci \& Ryan, 2000). Supporting this element of the grounded theory, we suggest that by allowing the 'high performers' to miss training or games when coaches or players deemed it unnecessary for them to attend, a series of events occurred. The coaches were thwarting the players’ psychological need for relatedness by indirectly encouraging them to remove themselves from the group, thwarting the need for autonomy by telling the players not to attend, and thwarting the need for competence by begetting a perception that players could not develop through training or games any more. Conversely, in the 'low performers', their need for relatedness appears thwarted by being distanced from significant members of the group that could have been a learning asset or role model (i.e., the 'high performers'), their need for autonomy was thwarted by feeling they were not afforded the same freedom of choice and the perceived incongruent disciplinary sanctions that were placed on them should they miss training or games, and their need for competence was thwarted by the sense that they were not good enough to play with the 'high performers'. Essentially when players 


\section{CAREER DEVELOPMENT IN UK FEMALE SOCCER PLAYERS}

1 perceived themselves less 'soccer competent', their motivation for involvement decreased (cf.

2 Quested et al., 2013).

Further negative social interactions occurred with soccer peers. These typically happened when players subjectively (e.g., I think they're better than me) or objectively (e.g., youth international player) recognised their peers as more competent. This appeared to result in players using behavioural disaffection (e.g., Curran et al. 2013) as a reactive avoidance coping strategy. Players consciously, markedly reduced efforts in training or competition to avoid selection against a difficult team as well as self-deselecting for competitive games because they did not want to be over-shadowed by their international team-mates. Players also reported feeling over-whelmed by higher level players that they played alongside for their player development centre, and were often pre-occupied with the ramifications of making performance related mistakes (e.g., Larsen et al. 2013).

Coach level data suggested that it was often difficult to fully integrate all players in training sessions due to organisational stressors (e.g., lack of resources) and the range of technical ability within a group. As mid-late adolescent players are still learning soccer through the development and into the mastery stage (Wylleman \& Lavallee, 2004), and given the emphasis placed by coaches on the needs for technical and tactical skill development, we suggest the Challenge Point Framework (CPF; Guadagnoli \& Lee, 2004) as a noteworthy consideration to counteract issues of low resources and a wide range of abilities. The CPF offers that learning is intimately related to the information available to the learner and how the learner may interpret that information in a performance environment which - in turn - is linked to the functional difficulty of a task. Three key posits arise from this: (a) learning cannot occur in the absence of information from which one can learn; (b) learning will be reduced in the presence of too much or too little information; and (c) the optimal amount of information differs as a function of the technical ability of the learner and 


\section{CAREER DEVELOPMENT IN UK FEMALE SOCCER PLAYERS}

1 the difficulty if the task to be learned (Guadagnoli \& Lee, 2004). We suggest that, in allowing

2 high performers to miss training, coaches were removing a valuable learning resource for

3 lower performers. As opposed to letting high performers have 'time off', coaches could have

4 increased the degree of contextual interference for higher performers through increasing their

5 functional task difficulty (e.g. via tactical overload in a small-sided game). To support this aspect of the theoretical proposals, drawing on peer-learning literature from education

7 settings that has demonstrated the role of peers in enhancing academic achievement and motivation (e.g., Eisenkopf, 2010) we argue this would have challenged higher performers further whilst also maintaining their presence as a learning resource from which lower performers could develop. Intuitively, we contend that enhancing this capacity to learn may also enhance both soccer and education success, given that recent literature found some student-athletes to be determined to pursue both their education and sport, explaining that both connect the athlete's sense of identity, purpose and well-being (O’Neill et al. 2013).

We are cognisant here of not attributing socio-contextual or environmental factors as sole reasons for female soccer players’ unsuccessful attempts at junior to senior career transitions. Through their reported developmental behaviours (e.g. "nights out on the town" with peers on the night before training or games), players in this study appeared to lacked the necessary self-regulatory capacity to progress in female soccer (e.g., Gledhill \& Harwood, 2014) that can differentiate between higher and lower ability players (e.g., Toering, ElferinkGemser, Jordet, \& Visscher, 2009). Players also appeared to lack a sense of soccer social competence. During mid-adolescence, girls demonstrate a marked increase in the importance of peers and social relationships and will have a tendency to seek close relationships with their peers (Visek, Harris \& Blom, 2013). We suggest it is this tendency that meant players fell short of the required social competence (encompassing cognitive, affective and behavioural elements) required to make successful career transitions. This can be evidenced 


\section{CAREER DEVELOPMENT IN UK FEMALE SOCCER PLAYERS}

1 by players recognising that their lifestyles and social interactions were not those required of

2 an elite level player, yet they did not apply that learning to make adaptive changes in social interactions (Semrud-Clikeman, 2007).

The impact of social competence on talent development on career transitions is not a new phenomenon and has previously been shown to be related to dropout from male youth soccer (e.g., Ommundsen \& Valgum, 1991). However, little is known about how social competence can be developed in female soccer players to facilitate dual careers. Therefore, we suggest that a player education programme centered on the development of social competence may serve to increase the chance of successful junior to senior career transitions. We would however echo that those working with mid-adolescent female soccer players must remain mindful of the potential impact of the need for strong social relationships on the player (Visek et al. 2013) when considering such a programme.

\section{Applied implications}

Based on the propositions of the grounded theory, four prominent applied implications have emerged from this study. First; we have been mindful through this paper to avoid communicating a message that soccer is more important than education. However, we do suggest that the two should mutually co-exist from an early age in aspiring female soccer players. Existing literature suggests that consideration of dual career development can reduce dropout and aid junior to senior career transitions in sport (e.g., Larsen et al. 2013;

Stambulova, Franck, \& Weibull, 2012; Warriner \& Lavallee, 2008). This is a particularly important consideration for female soccer players in the UK given that - even in the more professional structure offered by the FAWSL - there are currently few opportunities for soccer to provide the long-term economic stability that is afforded male players of an equivalent level, making the importance of a successful academic or vocational career a central consideration. As an example based on conjecture, many UK Higher Education 


\section{CAREER DEVELOPMENT IN UK FEMALE SOCCER PLAYERS}

1 Institutions offer athletic scholarships for female soccer players that have both academic and

2 sporting representative requirements. At the same time, a player may also be contracted to a

3 team in the UK FAWSL where their contract may stipulate that they cannot play

4 competitively for any other team. This will likely cause a situation where a female player is

5 required to forego either their academic or soccer career, thus threatening their dual career

6 potential. This is different to other countries (e.g., the USA) where the dual careers of female

7 soccer players are facilitated through the collegiate/university structure in such a manner that

8 supports soccer and education equally (McCormack \& Walseth, 2013), and can feed into elite

9 sport settings. Therefore, commensurate with recommendations in the EU guidelines on Dual

10 Careers of Athletes (European Commission, 2012), we suggest there is a need for

collaborations between national governing bodies, player development centres and education providers that can facilitate the dual career development of female soccer players in the UK.

Second; role strain emerged as a central threat to career transitions in female soccer.

We recommend the development of player education programmes or workshops that aid players in managing the impact of role strain, through effective role-strain management strategies. Moreover, given that part of the role strain was founded on the players' inability to make independent informed decisions that would benefit their soccer talent development trajectory, combined with the contention that reflective skills are a differentiating factor between elite and non-elite players (e.g., Toering et al, 2009); we also suggest the inclusion of reflective thinking skills training as part of player education workshops.

Third, educational programmes aimed at helping coaches, parents and teachers better understand dual careers in female youth soccer players would be a worthwhile future direction. We contend that these social agents have unintentionally collaboratively contributed to the players' crisis transitions (Stambulova, 2003) by fostering an environment whereby by the player has perceived a mismatch between their available resources and the 


\section{CAREER DEVELOPMENT IN UK FEMALE SOCCER PLAYERS}

1 demands of their within-career transition. This is particularly important for those working

2 with talented female soccer players in the 14-18 age range as it appears this age range is where a player's multiple social identities demonstrate the greatest conflict. Further, we suggest that such education programmes adopt a family-systems approach whereby delivery

5 is player-centred whilst also being coach, parent and teacher supported. This will allow

6 players, coaches, parents and teachers to understand their interactions with each other, as well

7 as understanding their interactions with their environment (e.g., Blom, Visek \& Harris, 2013).

Finally, coach and player level data highlighted a lack of perceived competence on the part of coaches for player development beyond the technical and tactical level. Based on this and in-keeping with coaches’ preferred sources of coach education (e.g., Erickson, Bruner, MacDonald, \& Côté, 2008); we suggest that a collaborative, in-situ field-based learning, critical friend approach (cf. Cropley, Miles \& Peel, 2012) where coaches work with other professionals (e.g., sport psychologists) and focussing specifically on the (counter) transference of coach education into coaching behaviours may be noteworthy. This collaborative working alliance approach (cf. de Haan, 2011) to reflective practice that embraces both reflection in action as well as reflective on action may be fruitful in enhancing research informed coaching practices.

\section{Limitations}

The first limitation of our study was the absence of parent data. Without this, we are dependent on the views of players about their individual player-parent dyads. In defence of this; during data collection players often appeared concerned about the impact on their relationships with their parents should the parents be invited to interview and topics such as players' adolescent lifestyles and social relationships be discussed, so we deemed it unethical to sample parents. A second potential limitation was the reliance on retrospective interviews. Retrospective interviews can be subject to recall error or bias (Patton, 2002) which may 


\section{CAREER DEVELOPMENT IN UK FEMALE SOCCER PLAYERS}

1 distort the veracity of findings. In order to minimise this concern, we triangulated data from

2 players and the multiple social agents as well as adopting appropriate types of probe

3 questions (e.g., clarification, elaboration) during interviews. Future research may seek to

4 adopt more prospective approaches to research that incorporate behavioural observations in

5 order to further minimise the risk of recall error or bias. The final limitation is that the

6 grounded theory makes proposals about the conditions of an optimal learning and talent

7 development environment which, when met, offer a greater chance of effective within-career

8 transitions in female soccer. However the key proposals of the theory have yet to be tested.

9 As such, further applied research examining the application of this theory, overtly

10 considering the experience of players who are currently successful within their soccer

11 careers, is warranted.

12 Concluding remarks

To our knowledge this is the first study that has adopted a combined grounded theory and negative case analysis perspective to examine talent development and career transitions in female soccer. Our findings have reflected the voices of the female soccer players and other transitional variables in the form of multiple social agents. In doing so, we have helped to gain a culturally specific understanding of the nature of their lived experiences within UK female soccer. We have forwarded that recognition by peers, education providers, parents and siblings of the unique challenges that face UK-based female youth soccer players can help to ameliorate their dual career experiences. These transitional factors ultimately impact on a player's developmental choices and, thus, their chances of a successful transition from the development to mastery stage of their soccer career. We contend that a broader scale examination of players' perceptions of female specific soccer talent development environments will serve to enhance our understanding of the challenges faced by adolescent female soccer players and may assist in scholarly understanding of 
1 factors affecting junior to senior career transitions and dual career experiences in female

2 soccer.

\section{Acknowledgements}

The authors would like to thank XXXXXXXXXXXXXXXXXXXXXXXXXX for their informative comments and for stimulating debate around earlier versions of this manuscript.

\section{References}

Alfermann, D., \& Stambulova, N. (2007). Career transitions and career termination. In G. Tennenbaum \& R.C. Ecklund (Eds.), Handbook of sport psychology (pp. 712-733). Hoboken, NJ: John Wiley \& Sons.

Blom, L.C., Visek, A.J., \& Harris, B.S. (2013). Triangulation in youth sport: Healthy partnerships among parents, coaches and practitioners. Journal of Sport Psychology in Action, 4, 86-96.

Bloor, M. (2001). Techniques of validation in qualitative research: A critical commentary. In R. M. Emerson (Ed.), Contemporary field research (pp. 383-396). Prospect Heights, IL: Waveland Press.

Bruner, M., Munroe-Chandler, K., \& Spink, K. (2008). Entry into elite sport: A preliminary investigation of the transition experience of rookie athletes. Journal of Applied Sport Psychology, 20, 236 - 252.

Christensen, M.K. (2009). “An eye for talent”: Talent identification and the "practical sense” of top - level soccer coaches. Sociology of Sport Journal, 26, 365 - 382.

Christensen, M.K., \& Sørensen, J.K. (2009). Sport or school? Dreams and dilemmas for talented Danish football players. European Physical Education Review, 1, 115 - 133.

Clarke, N.J., \& Harwood, C.G. (2014). Parenting experiences in elite youth football: A phenomenological study. Psychology of Sport and Exercise, 15, 528 - 537. 


\section{CAREER DEVELOPMENT IN UK FEMALE SOCCER PLAYERS}

1 Corbin, J. (2009). Taking an analytic journey. In J.M. Morse, P.N. Stern, J. Corbin, B.Bowers, K.Charmaz, \& A.E. Clarke, Developing grounded theory: The second generation (pp. 35-53). Walnut Creek, CA: Left Coast Press.

Corbin, J., \& Strauss, A. (2008). Basics of Qualitative Research ( ${ }^{\text {rd }}$. Ed.). London: Sage

Cosh, S., \& Tulley, P.J. (2014). “All I have to do is pass”: A discursive analysis of student athletes' talk about prioritising sport to the detriment of education to overcome stressors encountered in combining elite sport and tertiary education. Psychology of Sport and Exercise, 15, $180-189$.

Creswell, J.W. (2013). Qualitative Inquiry and Design: Choosing Among Five Approaches ( $3^{\text {rd }}$ ed.). London: Sage

Cropley, B., Miles, A., \& Peel, J. (2012). Reflective practice: Value, issues, and developments within sports coaching. Sports Coach UK original research. Leeds, UK: SCUK

Curran, T., Hill, A.P., \& Niemiec, C.P. (2013). A conditional process model of children’s behavioural disaffection in sport based on self-determination theory. Journal of Sport \& Exercise Psychology, 35, 30-43.

De Haan, E. (2011). Back to basics: How the discovery of transference is relevant for coaches and consultants today. International Coaching Psychology Review, 6, 180 - 193.

Denzin, N.K. (1989). The Research Act: A Theoretical Introduction to Sociological Methods ( $3^{\text {rd }}$ ed.). Englewood Cliffs, NJ: Prentice Hall.

Eisenkopf, G. (2010). Peer effects, motivation and learning. Economics of Education Review, 3, $364-374$.

Erickson, K., Bruner, M., MacDonald, D., \& Côté, J. (2008). Gaining insight into actual and preferred sources of coaching knowledge. International Journal of Sport Science and Coaching, 3, 527-538. 


\section{CAREER DEVELOPMENT IN UK FEMALE SOCCER PLAYERS}

1 European Commission (2012). EU guidelines on dual careers of athletes: Recommended policy actions in support of dual careers in high-performance sport. Retrieved 15/03/2015 from http://ec.europa.eu/sport/policy/societal_role/dual_careers_en.htm

Fédération Internationale de Football Association. (2014). Women’s football development programmes and guidelines 2015-2018. Retrieved from http://www.fifa.com/mm/document/footballdevelopment/women/01/57/10/97/womensf ootballdevprogr_e.pdf

Football Association. (2012). 'Game Changer'. Retrieved from http://www.thefa.com/news/2012/oct/game-changer-womens-football

Gledhill, A., \& Harwood, C. (2014). Developmental experiences of elite female youth soccer players. International Journal of Sport and Exercise Psychology, 12, 150 - 165.

Goldberg, A. D., \& Chandler, T. J. L. (1991). Sport participation among adolescent girls: Role conflict or multiple roles? Sex Roles, 25,_213-224.

Guadagnoli, M.A., \& Lee, T.D. (2004). Challenge point: A framework for conceptualizing the effects of various practice conditions in motor learning. Journal of Motor Behaviour, 36, 212-224

Holt, N.L., \& Dunn, J.G.H. (2004). Toward a grounded theory of the psychosocial competencies and environmental conditions associated with football success. Journal of applied sport psychology, 16, 199 - 219.

Holt, N.L., \& Mitchell, T. (2006). Talent development in English professional football. International journal of sport psychology, 37, 77 - 98.

Holt, N.L., \& Tamminen, K.L. (2010a). Improving grounded theory research in sport and exercise psychology: Further reflections as a response to Mike Weed. Psychology of sport and exercise, 11, 405-413 


\section{CAREER DEVELOPMENT IN UK FEMALE SOCCER PLAYERS}

1 Holt, N.L., \& Tamminen, K.L. (2010b). Moving forward with grounded theory in sport and exercise psychology. Psychology of sport and exercise, 11, 419-422

Larsen, C.H., Alfermann, D., Henriksen, K., \& Christensen, M.K. (2013). Successful talent development in soccer: The characteristics of the environment. Sport, Exercise, \& Performance Psychology, 2, 190 - 206.

McCormack, C., \& Walseth, K. (2013). Combining elite women’s soccer and education: Norway and the NCAA. Soccer \& Society, 14, 887- 897

Morley, D., Morgan, G., McKenna, J., \& Nicholls, A.R. (2014). Developmental contexts and features of elite academy football players: Coach and player perspectives. International Journal of Sport Science and Coaching, 9, 217-232

Morse, J. M. (1995). The significance of saturation. Qualitative Health Research, 5, $147-149$.

Ommundsen, Y., \& Valgum, P. (1991). The influence of low perceived soccer and social competence on later dropout from sport: A prospective cohort study of young boys. Scandanavian Journal of Science and Medicine in Sports, 1, 180 - 188.

O’Neill, M., Allen, B., \& Calder, A.M. (2013). Pressure to perform: An interview study of Australian school-age athletes’ perceptions of balancing their schools and sporting lives. Performance Enhancement and Health, 2, 87 - 93.

Patton, M.Q. (2002). Qualitative evaluation and research methods (3rd ed). Newbury Park, CA: Sage.

Plummel, B., Harwood, C., \& Lavallee, D. (2008). Jumping to the next level: A qualitative examination od within-career transition in adolescent event riders. Psychology of Sport and Exercise, 9, 427 - 447.

Quested, E., Ntoumains, N., Vildarch, C., Haug, E., Ommundsen, Y., Van Hoye, A., ... Duda, J.L. (2013). Intentions to drop-out of youth soccer: A test of basic needs theory amng 
European youth from five countries. International Journal of Sport and Exercise Psychology, 11, 1-13

Roccas, S. \& Sagiv, L. (2010). Personal values and behaviour: Taking the cultural context into account. Social and Personality Psychology, 4, 30-41.

Rubin, H.J., \& Rubin, I.S. (2005). Qualitative interviewing: The art of hearing data (2 ${ }^{\text {nd }}$ ed.) Thousand Oaks, CA: Sage.

Semrud-Clikeman, M. (2007). Social competence in children. New York, NY: Springer Science + Business Media

Schwartz, S. (2006). Basic human values: Theory, measurement, and applications. Revue francaise de Sociologie, 47, 929-968.

Scott, D., \& Andersson, H. Women’s soccer. In A.M. Williams (Ed.). Science and Soccer: Developing Elite Performers (pp. 237-258). Abingdon, Oxon: Routledge.

Stambulova, N. (2003). Symptoms of a crisis-transition: A grounded theory study. Svensk Idrottpsykologisk Förenings Årsbook, 2003, 97-109.

Stambulova, N. (2009). Talent development in sport: A career transitions perspective. In E. Tsung-Min Hung, R. Lidor, \& D. Hackfort (Eds.). Psychology of Excellence (pp. 6374). Morgantown, WV: Fitness Information Technology.

Stambulova, N.B., \& Alfermann, D. (2009). Putting culture into context: Cultural and crosscultural perspectives in career development and transition research and practice. International Journal of Sport and Exercise Psychology, 7, 292 - 308.

Stambulova, N., Engström, C., Franck, A., Linnér, L., \& Lindahl, K. (2014). Searching for an optimal balance: Dual career experiences of Swedish adolescent athletes. Psychology of Sport and Exercise, $x \times x, 1-11$. 


\section{CAREER DEVELOPMENT IN UK FEMALE SOCCER PLAYERS}

1 Stambulova, N., Franck, A., \& Weibulkl, F. (2012). Assessment of transition from junior to senior sports in Swedish athletes. International Journal of Sport \& Exercise Psychology, 10, 1-17.

Stambulova, N.B., \& Ryba, T.V. (2014). A critical review of career research and assistance through a cultural lens: Towards a cultural praxis of athletes' careers. International Review of Sport and Exercise Psychology, 7, $1-17$.

Stambulova, N., \& Wylleman, P. (2014). Athletes’ career development and transitions. In A. Papaioannou, \& D. Hackfort (Eds.). Routledge companion to sport and exercise psychology (pp. 605-621). London: Routledge.

Strauss, A., \& Corbin, J. (1998). Basics of qualitative research: Techniques and procedures for developing grounded theory (2nd ed.). Newbury Park, CA: Sage.

Tamminen, K.A., \& Holt, N.L. (2010). Improving grounded theory research in sport and exercise psychology: Further reflections as a response to Mike Weed. Psychology of Sport and Exercise, 11, 405 - 413.

Toering, T.T., Elferink - Gemser, M.T., Jordet, G., \& Visscher, C. (2009). Self - regulation and performance level of elite and non - elite youth soccer players. Journal of Sports Sciences, 27, $1509-1517$

Tracy, S.J. (2010). Qualitative quality: Eight 'big-tent' criteria for excellent qualitative research, Qualitative Inquiry, 16, 837-851.

Visek, A.J., Harris, B.S., \& Blom, L.C. (2013). Mental training with youth sport teams: Developmental considerations and best-practice recommendations. Journal of Sport Psychology in Action, 4, 45-55.

Weed, M. E. (2009). Research quality considerations for grounded theory research in sport \& exercise psychology. Psychology of Sport and Exercise, 10, 502-510. 


\section{CAREER DEVELOPMENT IN UK FEMALE SOCCER PLAYERS}

1 Wylleman, P., Alfermann, D., \& Lavallee, D. (2004). Career transitions in sport: European perspectives. Psychology of Sport and Exercise, 5, 7-20.

Wylleman, P., \& Lavallee, D. (2004). A developmental perspective on transitions faced by

6

7

8

9

10

11

12 athletes. In M. Weiss (Ed.) Developmental sport and exercise psychology: A lifespan perspective (pp. 507 - 527). Morgantown, WV: Fitness Information Technology.

6

7


Data collection and analysis

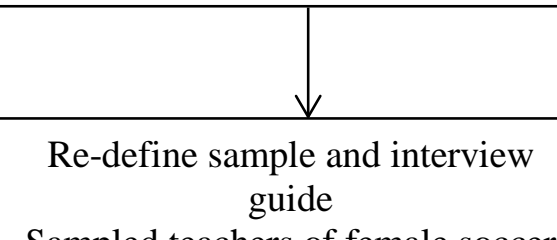

Sampled teachers of female soccer players $(n=8)$

\section{Data collection and analysis}

Fig. 1. Theoretical sampling 


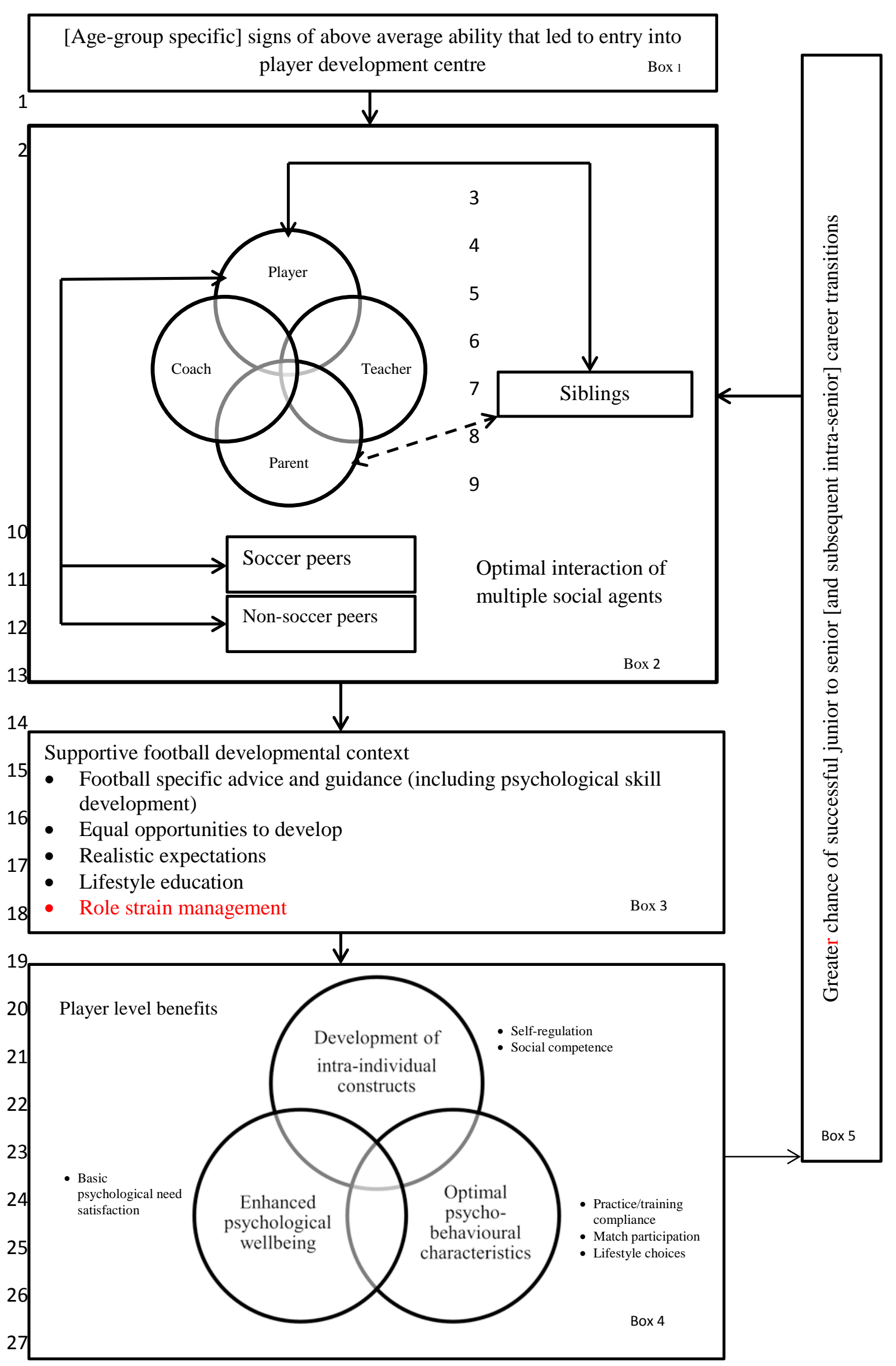

28 Fig 2. A Grounded theory of talent development and career transitions in female soccer 
CAREER DEVELOPMENT IN UK FEMALE SOCCER PLAYERS 